\title{
Andreas Weiglein (1961-2020): exemplary clinical anatomist and respected colleague
}

\author{
Cristian Stefan (iD) \\ Department of Molecular Pathobiology, New York University College of Dentistry, New York, USA \\ Anatomy 2020;14(1):7-9 @2020 Turkish Society of Anatomy and Clinical Anatomy (TSACA)
}

During a time when faculty members, departments and societies related to the field of anatomy have strived to align themselves with the clinical dimensions and applications of this discipline, Andreas H. Weiglein was, and will always be, remembered as a highly respected academic and a personification of what a Clinical Anatomist truly represents. He brought the symbiotic relationship between anatomy and its clinical relevance to the highest possible level, not only through commitment, diligence, perseverance and creativity, but also through his natural ability to interconnect the dots of multiple fields. Andreas was able to see the essence of the living body in the context and perspective of the entire medical and dental curriculum and across all health care professions.
Born, raised and educated in the charming historical city of Graz, Austria, Andreas received the MD degree from the Karl-Franzens University Medical School in 1988. He started his academic career in 1988 as an Assistant Professor in the Anatomical Institute at his alma mater. In 1996 he was promoted to Associate Professor and Vice Chair at the same institution. Andreas assumed essential administrative tasks in the numerous courses, programs, projects and initiatives in which he was involved, often with a leadership role.

Throughout his career, Andreas was very active in many local, national and international professional associations and venues. Meeting Andreas at one of these occasions was a great opportunity to listen to his exqui-

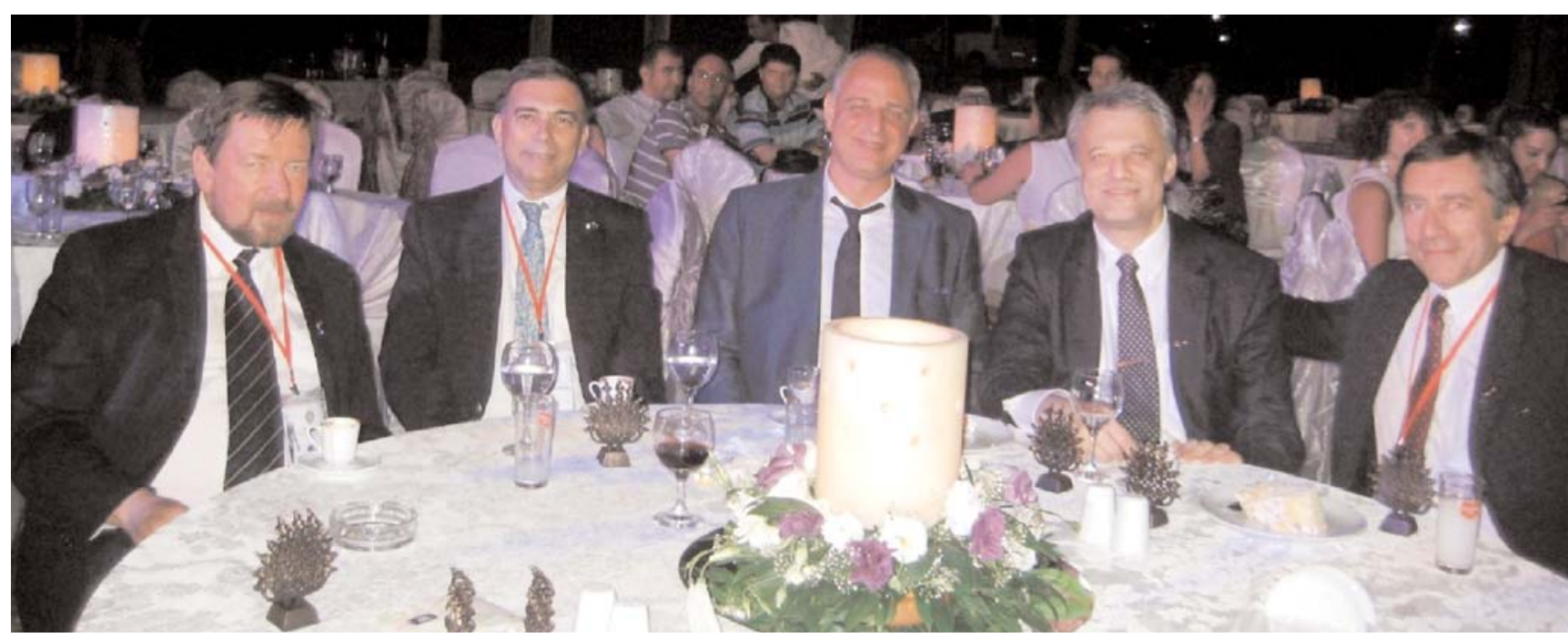

Figure 1. Gala dinner picture from the 4th International Symposium of Clinical and Applied Anatomy, 28 June-1 July 2012, Ankara, Turkey. We celebrated Andreas' birthday that night. From left to right: Andreas H. Weiglein (Austria), Antonio Gonçalves-Ferreira (Portugal), Salih Murat Akkın (Turkey), Cristian Stefan (USA) and Fabrice Duparc (France). 


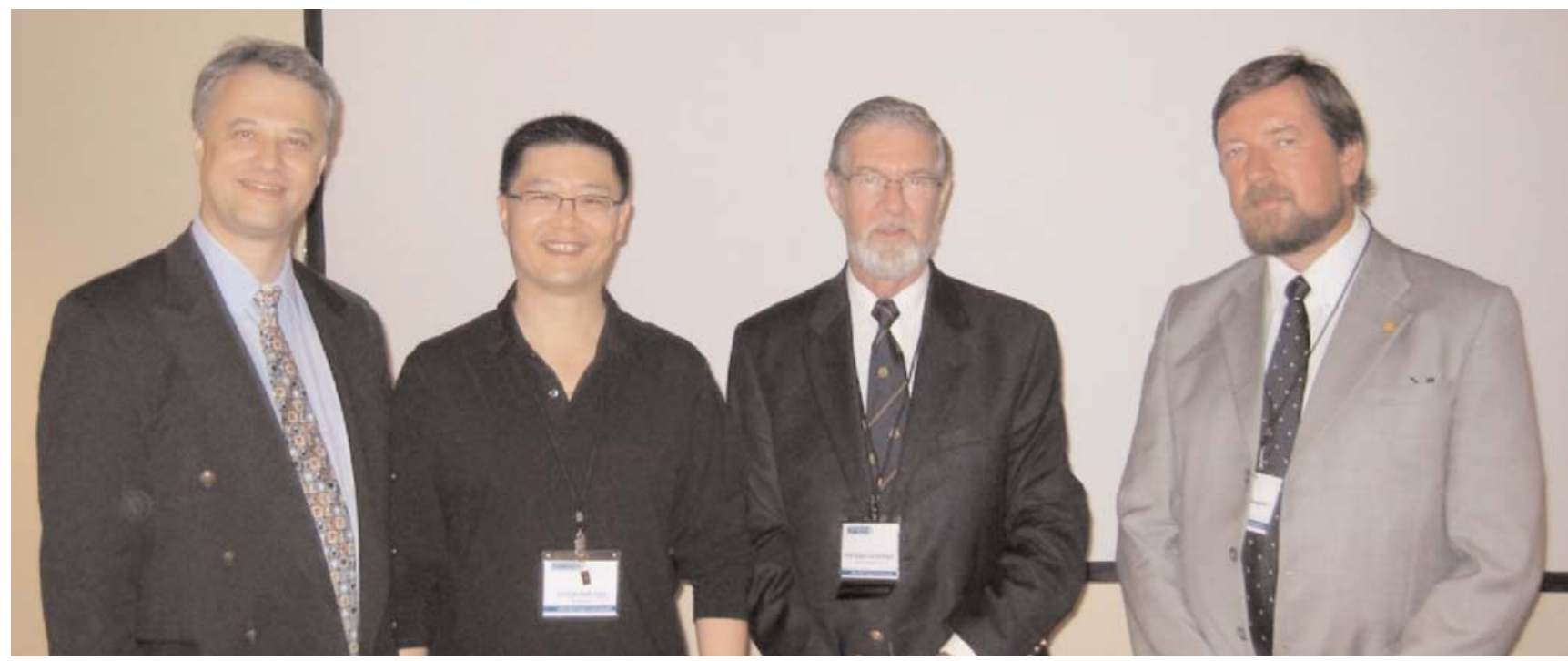

Figure 2. Panelists on a symposium at the Association for Medical Education in Europe Annual Conference in Prague 2008. From left to right: Cristian Stefan (USA), Goh-Poh Sun (Singapore), Allan Carmichael (Australia) and Andreas Weiglein (Austria).

site presentations, learn from his rich experience, explore new possibilities and approaches, and be inspired for further projects. It was also a real pleasure to exchange ideas with a wonderful colleague and establish a long-lasting friendship with him. Frequently listening with an enigmatic smile, Andreas did not rush into speaking, but when he spoke, each sentence conveyed a deep understanding often with a unique perspective. No matter if he were talking to a large audience or to a small group, he easily held the attention of everybody due to his erudition, clarity of thought, accuracy and precision in expression. Moreover, he had a great and very appropriate sense of humor.

Therefore, it is not surprising that Andreas was well known in academic circles and was invited around the world as a speaker, presenter, moderator and contributor to panels, workshops and symposia. His leadership qualities extended to the international level. He was President

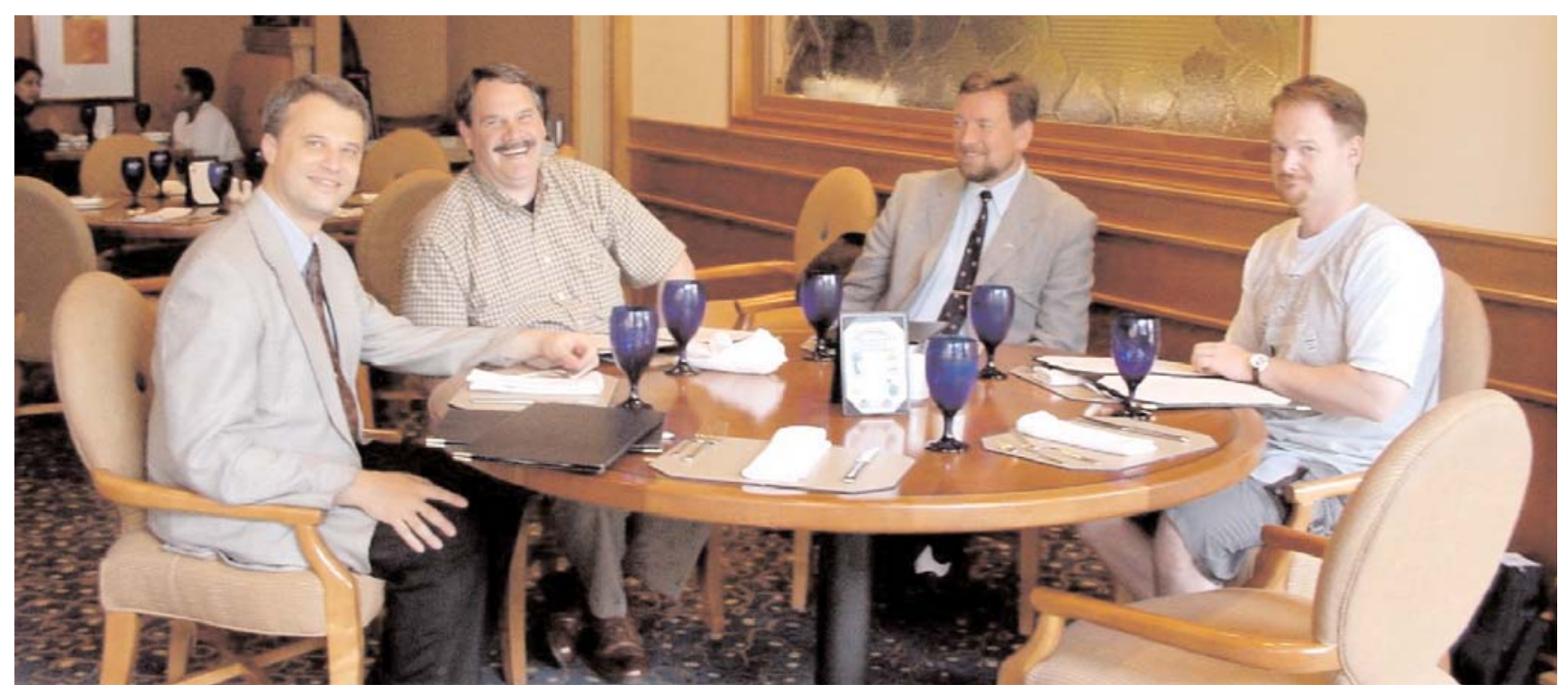

Figure 3. Another great moment with Andreas at the American Association of Clinical Anatomists Annual Meeting, Gainesville, FL, USA, 2002. From left to right: Cristian Stefan (USA), Thomas Quinn (USA), Andreas Weiglein (Austria), Neil Norton (USA). 
or Councilor of the European Association of Clinical Anatomy; President, Vice-President or Secretary for the International Society for Plastination; Councilor of the American Association of Clinical Anatomists; Honored Member of the Turkish Society of Anatomy and Clinical Anatomy, Honored Member of the Argentine Association of Clinical Anatomists, to name a few. He also had a central role in organizing several important meetings, including the 7th International Conference on Plastination; the First Joint Meeting of the American Association of Clinical Anatomists and European Association of Clinical Anatomy; and the 5th International Symposium on Clinical and Applied Anatomy.

In addition to an impressive list of publications, abstracts, presentations and contributions to books and his activity as editor, co-editor or reviewer for several journals, one of the most important aspects of Andreas' impact on the academic environment was his dedication to undergraduate and postgraduate education. He was a role model for students and young physicians alike in the

ORCID ID:

C. Stefan 0000-0003-0211-5277

deomed many and diverse programs he conducted or participated in.

Beyond and above the transmission of knowledge and skills, Andreas' strongest legacy was his enthusiastic and relentless effort to encourage active and life-long learning, facilitate critical thinking and instill professionalism in all of those who had the privilege to be in his presence for a longer or shorter period of time. He was always interested in finding innovative, creative and effective instructional formats in addition to traditional methods to accomplish short, and especially long-term, educational goals.

Because the true clinical dimension of anatomy was so clear and meaningful to Andreas as a way to enrich the study and practice of medicine seen in its complexity as both art and science, his vision and multifaceted work will persist not only through a rich and valuable collection of articles, books and methodology but will remain alive in all of us who knew him, to inspire us and therefore extend its light to so many generations to come.
Correspondence to: Cristian Stefan, MD

Department of Molecular Pathobiology, New York University College of Dentistry, 345 East 24th Street, 902B, New York, NY 10010, USA Phone: +1-212-998-9914

e-mail: cs4730@nyu.edu

Conflict of interest statement: No conflicts declared.

This is an open access article distributed under the terms of the Creative Commons Attribution-NonCommercial-NoDerivs 3.0 Unported (CC BY-NCND3.0) Licence (http://creativecommons.org/licenses/by-nc-nd/3.0/) which permits unrestricted noncommercial use, distribution, and reproduction in any medium, provided the original work is properly cited. Please cite this article as: Stefan C. Andreas Weiglein (1961-2020): exemplary clinical anatomist and respected colleague. Anatomy 2020;14(1):7-9. 